\title{
Is it unprofessional for doctors to have tattoos or facial piercings?
}

\author{
n Cite as: CMAJ 2018 August 27;190:E1026-7. doi: 10.1503/cmaj.109-5641
}

Posted on cmajnews.com on Aug. 8, 2018.

W hen imagining a doctor, many people picture a clean-cut, conservatively dressed person in a crisp, white lab coat. Almost never do they conjure electric blue hair, an octopus tattoo, or a row of eyebrow piercings yet these sorts of looks have become more common and accepted in modern society. If young doctors follow suit, will it become a problem in the conservative world of medicine?

Studies have long suggested that patients care about how health care providers look, and that they want them to look like that picture in their head. In surveys, patients have indicated that they prefer their doctors wearing formal clothing, such as a "neat blouse" and "smart pants" for women, and "collared shirts" and "smart shoes" for men. Many patients feel most comfortable when there's a white coat on top.

Given that, it's not surprising that things like piercings, tattoos and neon hair are controversial. One study found that nose and lip piercings were associated with lower ratings of competency and trustworthiness by both patients and medical colleagues. In another, female health care providers with unconventional body piercings were seen as less confident, professional, efficient and approachable than non-pierced peers. Yet another showed that patients rated tattooed health care providers lower than untattooed providers, and the ratings fell even further if providers had facial piercings. It seemed to be true regardless of whether the patient was rural or urban, male or female, old or young.

This is concerning, because patient satisfaction is correlated with outcomes. A satisfied patient is more likely to appear

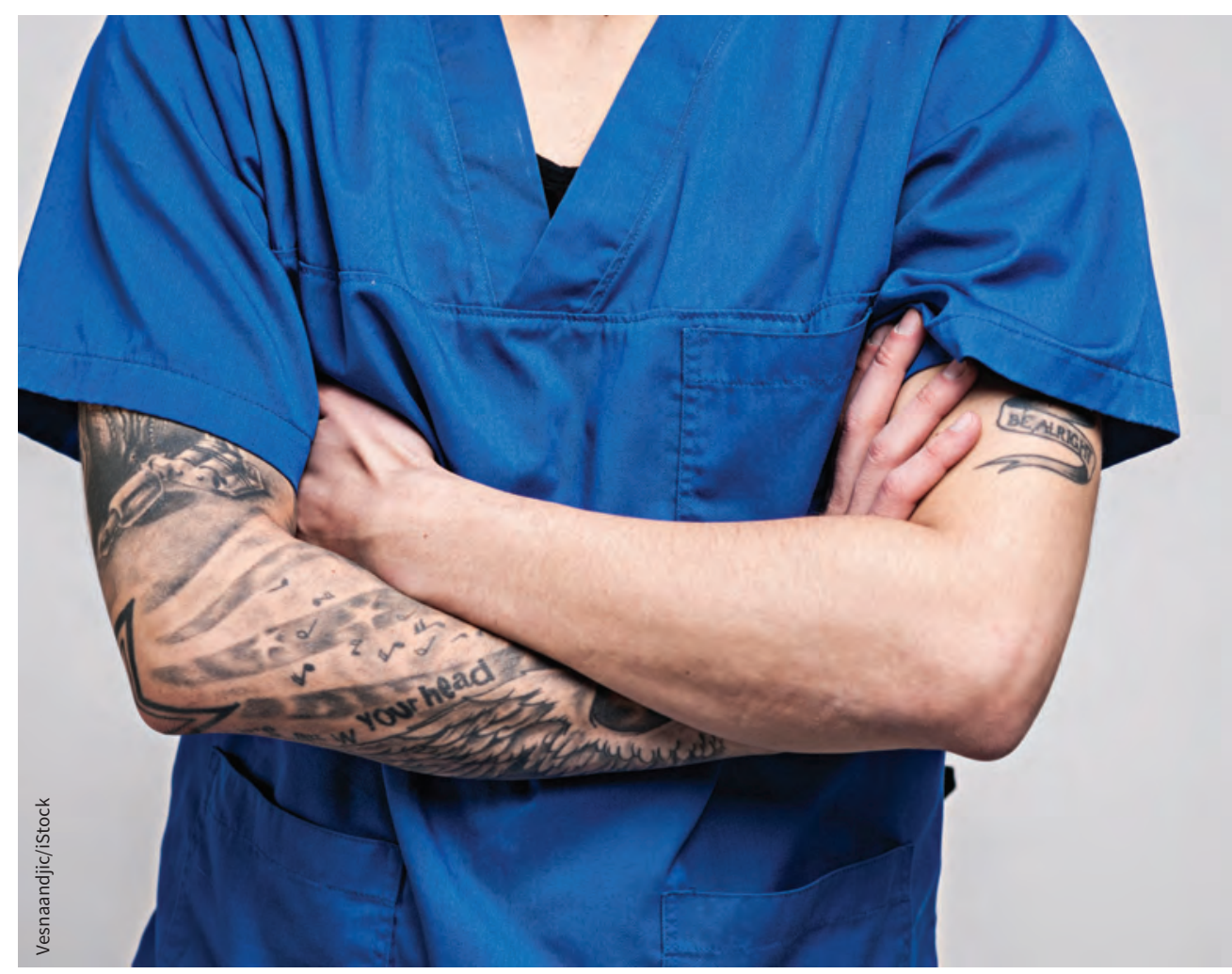

A recent study of emergency room patients found they didn't care if their doctors had body art or piercings.

for follow-up scans, to heed instructions on managing disease, and to take prescribed medications.

But all the above studies were conducted by asking patients how they would feel, hypothetically, about practitioners depicted in photos. Dr. Rebecca Jeanmonod and her colleagues at St. Luke's University Health Network in Pennsylvania wanted to know what happens in the real world, with real doctors.

Four male and three female emergency doctors agreed to wear temporary body art while they went about their regular work. They wore an arm tattoo, a piercing, both, or none. For females, the piercing was a prominent nose stud, and for males, it was a hooped earring. One male doctor dropped out because he felt uncomfortable wearing body art. Another male had a real tattoo, so his "none" condition involved keeping it covered.

After a patient interacted with one of these doctors, a nurse surveyed the patient about the physician's competence, professionalism, caring, approachability, trustworthiness and reliability. Body art was not mentioned. Each doctor's "clean" unadorned appearance served as the control. The researchers found that in the 924 interactions studied, ratings were unaffected by body art. Jeanmonod, who 
participated in the study, says that she received no negative comments on her piercings and tattoos, but quite a few positive ones. She notes that a high proportion of patients seen in the emergency department have tattoos and piercings.

Many medical institutions have strict policies about jewelry, tattoos, hair colour and male facial hair, among other things, but Jeanmonod thinks it may be time to revisit them. "It's not the patients who have a problem with it," she says, at least in emergency rooms. "It's more something we impose on one another."

Leanna Graham, director of professional practice and policy at the Univer- sity Health Network in Toronto, says that although they take a hard line on fashion that affects safety or infection control, such as open-toed shoes, they try to be open-minded in how they define professionalism. "The dress code in a workplace setting has to be in sync with who your patient population is," she says. "It's grey."

That greyness can be hard for some young doctors, however. Last year, medical students in the United Kingdom called on the British Medical Association to issue clear guidelines on what was and was not acceptable. The students argued there was too much inconsistency, and that for young doctors, proper dress was a "minefield." (The Canadian Federation of Medical Students say they have not formally discussed the issue.)

Erika Abner, in charge of ethics and professionalism curriculum at the University of Toronto Faculty of Medicine, says there is nothing specific in their curriculum about body art, or even about clothing. Students are asked to dress "appropriately" and they almost always do. "Most of the students dress conservatively," she says. "I see very little body art or multiple piercings."

Alison Motluk, Toronto, Ont. 